\title{
CART mitigates oxidative stress and DNA damage in memory deficits of APP/PS1 mice via upregulating $\beta$-amyloid metabolism-associated enzymes
}

\author{
HUI JIANG ${ }^{1}$, FENGNAN NIU ${ }^{1}$, YAN ZHENG ${ }^{2}$ and YUN XU ${ }^{1}$ \\ ${ }^{1}$ Department of Neurology, Affiliated Drum Tower Clinical Medical College of Nanjing Medical University; \\ ${ }^{2}$ Departnment of Neurology, Affiliated Hospital of Nanjing University of Traditional Chinese Medicine, \\ Nanjing, Jiangsu 210000, P.R. China
}

Received July 23, 2020; Accepted December 17, 2020

DOI: $10.3892 / \mathrm{mmr} .2021 .11919$

\begin{abstract}
Alzheimer's disease (AD) is the most common form of dementia that is primarily characterized by progressive cognitive deficits. The toxicity of amyloid $\beta$-protein $(A \beta)$ serves an important role in the progression of $A D$, resulting in neuronal loss via a number of possible mechanisms, including oxidative stress, mitochondrial dysfunction, energy depletion, apoptosis and neuroinflammation. Previous studies have reported that cocaine amphetamine regulated transcript (CART) treatment improves memory and synaptic structure in APP/PS1 mice. Therefore, the present study aimed to investigate whether CART served a protective role against memory deficits in AD. APP/PS1 mice were treated with CART or PBS. Spatial memory was assessed using the Morris water maze. Oxidative stress and DNA damage were compared among wild-type, APP/PS1 and CART-treated APP/PS1 mice. The mRNA and protein expression levels of $A \beta$ metabolism-associated enzymes, including neprilysin (NEP), insulin-degrading enzyme (IDE), receptor for advanced glycation end products (RAGE) and low-density lipoprotein receptor-related protein 1 (LRP-1), in the hippocampus were measured via reverse transcription-quantitative PCR and western blotting, respectively. CART improved the memory impairment of APP/PS1 mice by reducing oxidative stress, inhibiting DNA damage and protecting against mitochondrial dysfunction in the cerebral cortex and hippocampus. CART also reduced cell senescence and oxidative stress in A $\beta 1$-42-exposed primary cortical neurons in APP/PS1 mice. Moreover, CART promoted A $\beta$ degradation via modulating $A \beta$ metabolism-associated enzymes, including IDE, NEP, LRP-1
\end{abstract}

Correspondence to: Dr Yun Xu, Department of Neurology, Affiliated Drum Tower Clinical Medical College of Nanjing Medical University, 321 Zhongshan Road, Nanjing, Jiangsu 210000, P.R. China

E-mail: xuyun@njglyy.com

Key words: cocaine amphetamine regulated transcript, Alzheimer's disease, $\beta$-amyloid protein, oxidative stress, DNA damage and RAGE. Collectively, the present study indicated that CART improved the learning and memory capacity of APP/PS mice, thus may have potential to serve as a novel therapeutic agent for AD.

\section{Introduction}

Alzheimer's disease (AD) is a common neurodegenerative disease that occurs in the elderly population and is characterized by progressive memory loss, mental decline and behavioral abnormalities (1). Along with an increased aging population, the global incidence of AD has increased rapidly in recent years, affecting the health of patients (2). Previous statistics have indicated that the prevalence of AD in elderly patients $>80$ years old is $30 \%$, and the number of patients with $\mathrm{AD}$ worldwide is estimated to be $\sim 26$ million (3).

The regions of the brain most frequently involved in the characteristic pathological alterations associated with AD include those required for advanced cognitive functions, especially the neocortex and hippocampus (4). At present, senile plaque (SP) formation, neurofibrillary tangles, neuronal loss (5), and the formation, metabolism and toxicity of $\beta$-amyloid protein $(\mathrm{A} \beta)$ are considered to be the core of AD pathogenesis (6). Recent data from cellular and animal models proposed that $A \beta$ deposition is preceded by intraneuronal accumulation of the direct precursor of A $\beta, C 99$ (7). Previous studies have suggested that $A \beta$ may lead to neuronal damage via neurotoxic excitotoxicity, mitochondrial dysfunction, abnormal energy metabolism, calcium homeostasis and apoptosis (8). Moreover, it has been reported that oxidative stress serves a vital role in the pathological processes of $\mathrm{AD}$, causing damage to the body when the generation of oxygen free radicals exceeds the limits of the antioxidant system in the pathological environment (9). The available treatment strategies for AD function via suppressing the formation of $A \beta$, preventing the accumulation of $A \beta$ to form SPs, reducing the amount of lysis in the brain and depolymerizing SPs (10-12). Transcription factor EB, which regulates C99 accumulation in AD cellular models, serves as a potential strategy to prevent the accumulation of this early neurotoxic catabolite (7). Furthermore, certain A $\beta$-associated enzymes can regulate the metabolism of plaques, including neprilysin 
(NEP) (13), insulin-degrading enzyme (IDE) (14), receptor for advanced glycation end products (RAGE) (15) and low-density lipoprotein receptor-related protein 1 (LRP-1) (16).

Cocaine and amphetamine regulated transcript (CART) is a hypothalamic neuropeptide that is involved in feeding, locomotor activity and conditioned place preference (17). CART is widely expressed in central and peripheral neurons, as well as in endocrine cells (18). The known expression sites include the brain, adrenal gland, pancreas and gastrointestinal tract. In the brain, CART serves an important role in physiological and pathological processes, including eating, stress and drug dependence, and it has been used as an effective treatment for a variety of central nervous system diseases $(4,19)$. In the pancreas, CART serves a physiological role in regulating both endocrine and exocrine pancreatic secretions (20). CART also regulates islet hormone secretion (21) and gastrointestinal tract motility (22). A previous study demonstrated that CART is positively associated with oxidative stress (23). However, the potential molecular mechanism underlying the central role of CART is not completely understood.

Our previous studies confirmed that CART improved memory and synaptic structures, and modulated the expression of $\mathrm{A} \beta$ metabolism-associated enzymes in an $\mathrm{AD}$ mouse model in APP/PS1 mice $(4,24)$. In the present study, whether CART improved cognitive function by inhibiting oxidative stress in an AD mouse model in APP/PS1 mice was investigated with the aim of identifying a potential therapeutic strategy for $\mathrm{AD}$.

\section{Materials and methods}

Animals and treatment. A total of 30 male APP/PS1 transgenic mice (25-30 g; 8 months old) and wild-type (WT) control mice (25-30 g; 8 months old) were purchased and housed in the Model Animal Research Center of Nanjing University. Mice were housed at $23-28^{\circ} \mathrm{C}$ with $30-60 \%, 12$-h light/dark cycles, and free access to food and water.

All mice were of the C57BL/6J genetic background. CART peptides were synthesized by Phoenix Pharmaceuticals Inc. Mice were treated with CART peptides treated as previously described $(4,24)$ with a slight modification. Briefly, APP/PS1 and age-matched B6 control mice were randomly divided into CART-treated or normal saline-treated groups (10 mice per group). CART was injected via the tail vein daily for 10 days at a dose of $0.5 \mu \mathrm{g} / \mathrm{kg}$, and then injected daily intraperitoneally for 20 days. All experimental procedures were approved by the Nanjing University's Committee of Experimental Animal Administration (Nanjing, China).

Cell culture. Primary cortical neurons were isolated and cultured as previously described (25). Dissociated cortical cells were seeded $\left(2 \times 10^{5}\right.$ cells $\left./ \mathrm{ml}\right)$ into 6-well plates. Cells were cultured in DMEM (Gibco; Thermo Fisher Scientific, Inc.) supplemented with 10\% FBS (Gibco; Thermo Fisher Scientific, Inc.) and $1 \%$ penicillin/streptomycin (Gibco; Thermo Fisher Scientific, Inc.) and exposed to CART peptide $(0.4 \mathrm{nM}$; Phoenix Pharmaceuticals, Inc.) for $1 \mathrm{~h}$ at $37^{\circ} \mathrm{C}$, followed by incubation with A $\beta 1-42(2 \mu \mathrm{M}$; MedChemExpress) for $24 \mathrm{~h}$ at $37^{\circ} \mathrm{C}$.
Cell viability. Cell viability was assessed by performing the Cell Counting Kit-8 (CCK-8) assay (cat. no. GB707; Dojindo Molecular Technologies, Inc.) according to the manufacturer's protocol. Briefly, $10 \mu$ l CCK-8 solution was added to each well of a 96-well plate. Following incubation for $4 \mathrm{~h}$, absorbance was measured at a wavelength of $450 \mathrm{~nm}$ using a microplate reader. The effect of CART on cell viability was determined by calculating the cell viability percentage of CART treated cells compared with saline-treated cells.

Morris water maze (MWM). The MWM test was performed to evaluate spatial memory as previously described (26). On the 9th day of administration, mice underwent the MWM directional navigation test, which lasted for 5 days. Each day, mice were placed into the water from the midpoint of the pool wall in the order of I-IV quadrants. The time required for the mice to enter the platform from the water within $60 \mathrm{sec}$ was recorded as the escape incubation period. If the mice could not find the platform within $1 \mathrm{~min}$, the experimenter led the mice to the platform, recording an escape incubation period of $60 \mathrm{sec}$. Each training interval was $60 \mathrm{sec}$. For the cruise test, the platform was removed and mice were placed in the pool in the order of I-IV quadrants. Subsequently, the swimming time and the crossing times in each quadrant were recorded within $60 \mathrm{sec}$. The experimental data were recorded and analyzed using a camera and MWM software (version 1.0; Shanghai Information Technology Co., Ltd.).

Intracellular reactive oxygen species (ROS), 8-hydroxy2'-deoxyguanosine (8-OhdG) and neurotrophin-3 (3-NT) analysis. Following sacrifice by cervical dislocation, the cerebral cortex and hippocampus were isolated from each mouse and were homogenized in $2 \%$ SDS containing a protease inhibitor cocktail (Sigma-Aldrich; Merck KGaA) and phosphatase inhibitors (Calbiochem; Merck KGaA). The homogenized mixes were centrifuged at $100,000 \mathrm{xg}$ for $1 \mathrm{~h}$ at $4^{\circ} \mathrm{C}$. The supernatant was stored as soluble fraction to detect ROS (cat. no. E004-1-1; Nanjing Jiancheng Bioengineering Institute), 8-OhdG (cat. no. H165; Nanjing Jiancheng Bioengineering Institute) and 3-NT (cat. no. 267-N3; R\&D Systems, Inc.) according to the manufacturer's instructions (4).

Measurement of mitochondrial membrane potential. Mitochondria were isolated from the hippocampus and cortex sections using the Mitochondria Isolation kit (cat. no. G006-1-1; Nanjing Jiancheng Bioengineering Institute) according to the manufacturer's instructions. The mitochondrial membrane potential was detected using a mitochondrial membrane potential assay kit (cat. no. G009-1-3; Nanjing Jiancheng Bioengineering Institute) according to the manufacturer's instructions (9).

Histology experiments. Cerebral cortex and hippocampus samples were isolated and frozen slices $\left(40-\mu \mathrm{m}\right.$ thick; $\left.-20^{\circ} \mathrm{C}\right)$ were prepared. Briefly, mice were anesthetized intra-peritoneally with $1 \%$ pentobarbital at a dose of $50 \mathrm{mg} / \mathrm{kg}$ and fixed on their back. The chest was opened to expose the heart and an infusion needle was inserted into the left ventricle, then the right atrial appendage was cut. Mice were perfused with $0.9 \%$ physiological saline for $10 \mathrm{~min}$ and then rapidly perfused with $4 \%$ precooled paraformaldehyde ( $\mathrm{pH}$ 7.4) for 
$30 \mathrm{~min}$. The brain was exposed by performing a craniotomy and fixed with $4 \%$ precooled paraformaldehyde at room temperature overnight. After $24 \mathrm{~h}$, the samples were rinsed with PBS for $4-5 \mathrm{~h}$ and incubated overnight at $4^{\circ} \mathrm{C}$. Samples were dehydrated with a 20 and $30 \%$ sucrose gradient, then sliced with a cryostat. Sections were stained using an anti-A $\beta$ antibody (cat. no. 8243; 1:200; Cell Signaling Technology, Inc.) as previously described (4). Briefly, tissue sections were dewaxed and hydrated, and antigen retrieval was performed with boiling citrate. Following washing three times with PBS for 5 min each time, tissue sections were incubated with $3 \% \mathrm{H}_{2} \mathrm{O}_{2}$-PBS for $30 \mathrm{~min}$ and washed three times with PBS for 5 min each time. Subsequently, tissue sections were incubated with $0.5 \%$ BSA-PBS (Sigma-Aldrich; Merck KGaA) at room temperature for $2 \mathrm{~h}$ followed by incubation with the primary antibody $\left(1: 200\right.$ in $0.5 \%$ BSA-PBS) overnight at $4^{\circ} \mathrm{C}$. Tissue sections were maintained at room temperature for $30-60 \mathrm{~min}$, washed three times with PBS for $5 \mathrm{~min}$ each time, then incubated with an HRP-labeled sheep anti-mouse/rabbit IgG polymer (1:10,000; cat. no. ab6795; Abcam) at room temperature for 1-2 h. Following washing three times with PBS for 5 min each time, tissue sections were stained with hematoxylin at room temperature for $3 \mathrm{~min}$. Then, $1 \%$ hydrochloric acid alcohol was extracted twice, rinsed with running water for 3 min, incubated with gradient alcohol and xylene for $2 \mathrm{~min}$. Finally, the slides were sealed and stained samples were visualized using a fluorescent microscope (magnification, x10).

Western blotting. Total protein was isolated from the cerebral cortex and hippocampus samples using RIPA buffer. Subsequently, western blotting was performed as previously described (27).Primary antibodies targeted against the following were used: IDE (cat. no. ab133561; 1:2,000; Abcam), NEP (cat. no. ab227195; 1:2,000; Abcam), LRP-1 (cat. no. sc-57352; 1:2,000; Santa Cruz Biotechnology Inc.), superoxide dismutase (SOD)-1 (cat.no. 10269-1-AP; 1:2,000; ProteinTech Group,Inc.), SOD-2 (cat. no. 66474-1-Ig; 1:2,000; ProteinTech Group, Inc.), $\gamma$-H2A histone family member X $(\gamma$-H2A.X; cat. no. ab2893; 1:2,000; Abcam), peroxiredoxin 1 (Prdx1; cat. no. 8499; 1:2,000; Cell Signaling Technology, Inc.), polycomb complex protein (Bmi-1; cat. no. 10832-1-AP; 1:2,000; ProteinTech Group, Inc.), p16 (cat. no. 80772; 1:2,000; Cell Signaling Technology, Inc.), TNFa (cat. no. 11948; 1:2,000; Cell Signaling Technology, Inc.), IL-1 $\beta$ (cat. no. 16806-1-AP; 1:2,000; ProteinTech Group, Inc.) and $\beta$-actin (cat. no. BS6007M; 1:2,000; Bioworld Technology, Inc.). Briefly, gels were placed into the electrophoresis tank, electrophoresis solution was added, protein and marker were added, the lid was covered and the gel was removed after electrophoresis. As for the transfer solution, the sponge, filter paper, gel and PVDF were pressed on the splint membrane, followed by filter paper and sponge. The membrane was placed into the transfer film tank with an ice pack and transfer solution, the lid was covered and the tank was maintained at a constant pressure of $0.28 \mathrm{~A}$ for $2 \mathrm{~h}$. All experiments were performed in at least triplicate.

$R N A$ extraction and reverse transcription-quantitative $P C R$ $(R T-q P C R)$. Total RNA was extracted from cells and tissues using TRIzol ${ }^{\circledR}$ reagent (Invitrogen; Thermo Fisher Scientific, Inc.). Total RNA was reverse transcribed into cDNA using
Table I. Sequences of primers used in the present study.

Gene $\quad$ Sequence $\left(5^{\prime} \rightarrow 3^{\prime}\right)$

$\begin{array}{ll}\text { IDE (mouse) } & \text { R: CAAACACTGTTTATGGACTG } \\ & \text { R: TGCTGAATTGAATGTGTACC }\end{array}$

Bmi-1 (mouse) F: ATCCCCACTTAATGTGTGTCCT R: CTTGCTGGTCTCCAAGTAACG

p16 (mouse) F: AACTCTTTCGGTCGTACCCC R: GCGTGCTTGAGCTGAAGCTA

IL-1 $\alpha$ (mouse) F: CGAAGACTACAGTTCTGCCATT

R: GACGTTTCAGAGGTTCTCAGAG

Sirt1 (mouse) F: GCTGACGACTTCGACGACG R: TCGGTCAACAGGAGGTTGTCT

NEP (mouse) F: GAAGACCGAAATGACCCA R: CGGATGTAGTCCCGTAAA

IL-6 (mouse)

F: CCAAGAGGTGAGTGCTTCCC

R: CTGTTGTTCAGACTCTCTCCCT

GAPDH (mouse) F: TGGATTTGGACGCATTGGTC R: TTTGCACTGGTACGTGTTGAT

RAGE (mouse) F: TCTTGGTGCCTTTTGTGTGAC R: CTCTTCCTCGTTTTTGCTCTC

Bmi-1 (human) F: CGTGTATTGTTCGTTACCTGGA R: TTCAGTAGTGGTCTGGTCTTGT

p53 (mouse)

F: GCGTAAACGCTTCGAGATGTT R: TTTTTATGGCGGGAAGTAGACTG

LRP-1 (mouse)

F: TCTTGGTGCCTTTTGTGTGAC R: CTCTTCCTCGTTTTTGCTCTC

SOD1 (mouse) F: AACCAGTTGTGTTGTCAGGAC R: CCACCATGTTTCTTAGAGTGAGG

SOD2 (mouse) F: CAGACCTGCCTTACGACTATGG R: CTCGGTGGCGTTGAGATTGTT

Nrf2 (mouse)

F: TCTTGGAGTAAGTCGAGAAGTGT

R: GTTGAAACTGAGCGAAAAAGGC

IDE, insulin-degrading enzyme; Bmi-1, polycomb complex protein; RANKL, receptor activator of NF- $\kappa \mathrm{B}$ ligand; NEP, neprilysin; RAGE, receptor for advanced glycation end products; LRP-1, low-density lipoprotein receptor-related protein 1; SOD, superoxide dismutase; Nrf2, nuclear factor, erythroid 2 like 2; Txnrd1, thioredoxin reductase $1 ; \mathrm{F}$, forward; $\mathrm{R}$, reverse.

the PrimeScript RT Reagent Kit (Takara Bio, Inc.) according to the manufacturer's instructions. Subsequently, qPCR was performed as previously described (28). The sequences of the primers used for qPCR are listed in Table I.

Statistical analysis. All experiments were repeated at least three times in a blinded manner. Data are presented as the mean \pm SEM. Comparisons between groups were analyzed using one-way ANOVA followed by Bonferroni's post hoc test. $\mathrm{P}<0.05$ was considered to indicate a statistically significant difference. All data were analyzed using SPSS software, version 18.0 (SPSS, Inc.). 


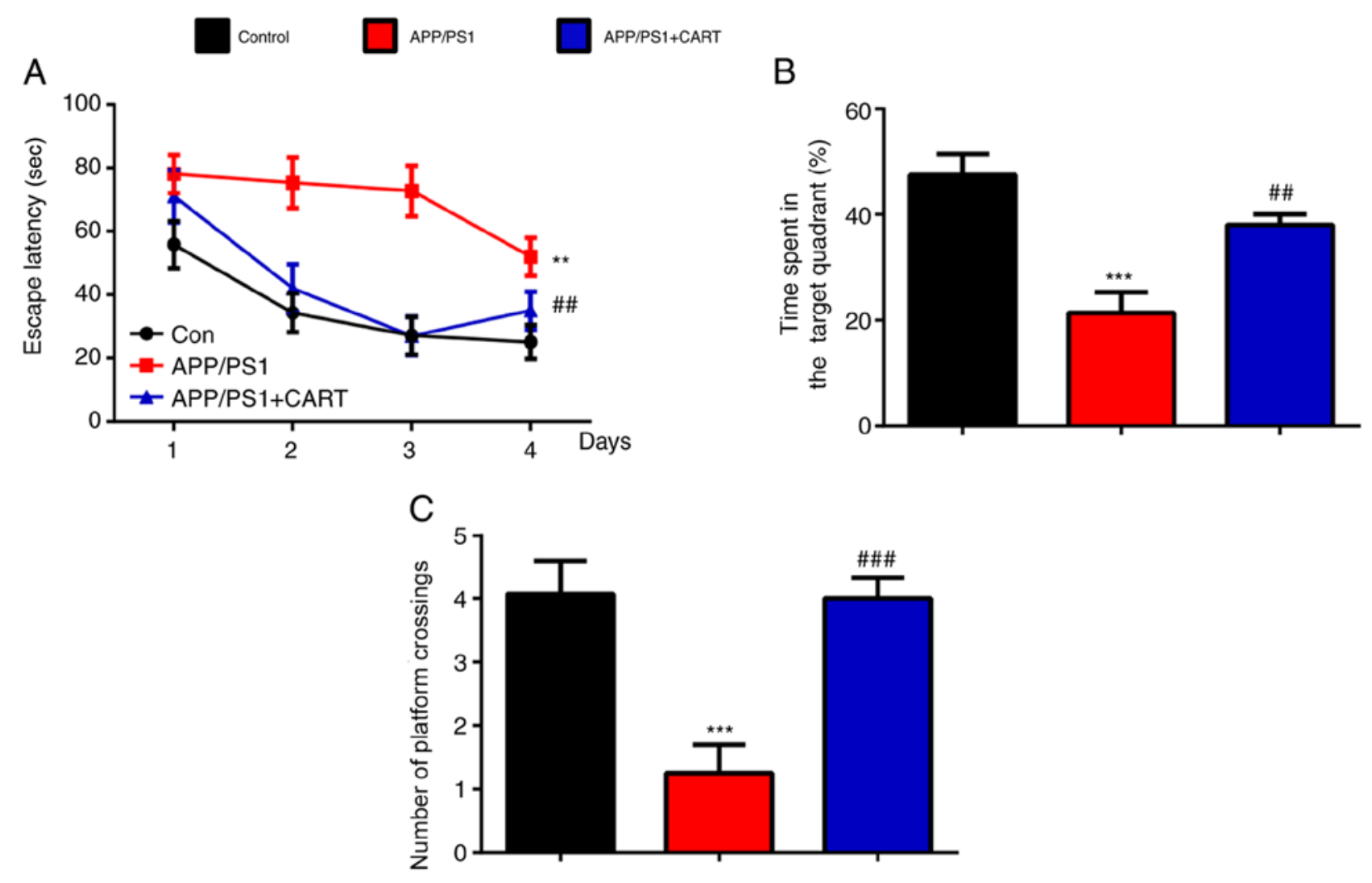

Figure 1. Exogenous CART supplements improve the memory impairment of APP/PS1 mice. WT, APP/PS1 and CART-treated APP/PS1 mice (age, 8 months) were used. (A) Escape latency in hidden platform task. (B) Time spent in target quadrant, the probe test session was performed $24 \mathrm{~h}$ after the training trials. (C) Number of platform crossings during the probe trial. Data are presented as the mean $\pm \mathrm{SEM}$ ( $\mathrm{n}=6$ per group). ${ }^{* *} \mathrm{P}<0.01$ and ${ }^{* * *} \mathrm{P}<0.001$ vs. control; ${ }^{\# \# \#} \mathrm{P}<0.05$ and ${ }^{\# \#} \mathrm{P}<0.01$ vs. APP/PS1. CART, cocaine amphetamine regulated transcript; WT, wild-type.

\section{Results}

CART treatment attenuates spatial memory impairment. MWM tests were performed to determine whether treatment with CART improved the spatial memory abilities of AD model (APP/PS1) mice. The escape latencies (Fig. 1A), time spent in the target quadrant (Fig. 1B) and the number of platform crossings (Fig. 1C) were significantly decreased in APP/PS1 mice compared with WT control mice, but were significantly increased in CART-treated APP/PS1 mice compared with untreated APP/PS1 mice. The results suggested that CART treatment significantly improved memory deficits in APP/PS1 mice.

CART modulates A $\beta$ metabolism-associated enzyme expression in the hippocampus and cerebral cortex. To investigate the mechanism underlying CART-mediated improvements in the spatial memory abilities of AD model mice, immunohistochemistry staining for $A \beta$ was performed. $A \beta$ expression was significantly increased in APP/PS1 mice compared with WT control mice, but significantly decreased in CART-treated APP/PS1 mice compared with untreated APP/PS1 mice (Fig. 2A and B). To investigate the mechanism underlying the effects of CART on A $\beta$ expression, the expression levels of $A \beta$ metabolism-associated enzymes were detected via RT-qPCR and western blotting. The protein and mRNA expression levels of IDE, NEP, and LRP-1 in the hippocampus (Fig. 2C-E) and cortex (Fig. 2F-H) were significantly decreased in APP/PS1 mice compared with WT control mice, but were significantly increased in CART-treated APP/PS1 mice compared with untreated APP/PS1 mice. Compared with WT control mice, RAGE mRNA expression was increased in untreated mice, and decreased in CART treated mice.

CART attenuates mitochondrial dysfunction by reducing oxidative stress and DNA damage in the cortex. The roles of CART treatment on the functional status of mitochondria, oxidative stress and DNA damage levels in WT, APP/PS1 and CART-treated APP/PS1 were assessed. 8-OHdG (Fig. 3A), 3-NT (Fig. 3D) and ROS (Fig. 3C) levels in the cerebral cortex tissues were significantly increased in APP/PS1 mice compared with WT control mice, but were significantly decreased in CART-treated APP/PS1 mice compared with untreated APP/PS1 mice. The mitochondrial membrane potential of the cerebral cortex tissues was significantly decreased in APP/PS1 mice compared with WT control mice, but was significantly increased in CART-treated APP/PS1 mice compared with untreated APP/PS1 mice (Fig. 3B).

In addition, the western blotting results indicated that protein expression levels of Bmi-1, SOD1 and PrdxI in the cortex were significantly decreased in APP/PS1 mice compared with WT control mice, but were significantly increased in CART-treated APP/PS1 mice compared with untreated APP/PS1 mice (Fig. 3E and F). Additionally, RT-qPCR demonstrated that mRNA expression levels of Bmi-1, SOD1, Sirt1 and nuclear factor erythroid 2 like 2 (Nrf2) in the cortex 


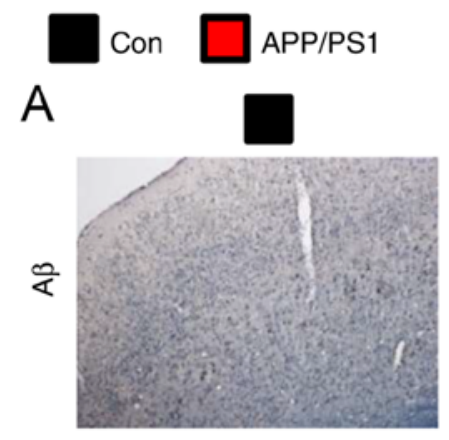

C

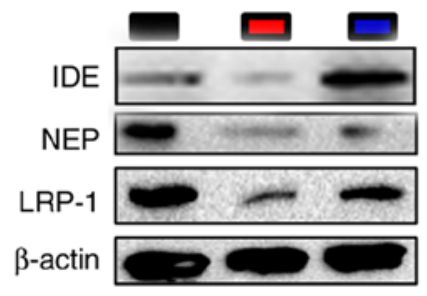

E
APP/PS1+high cart
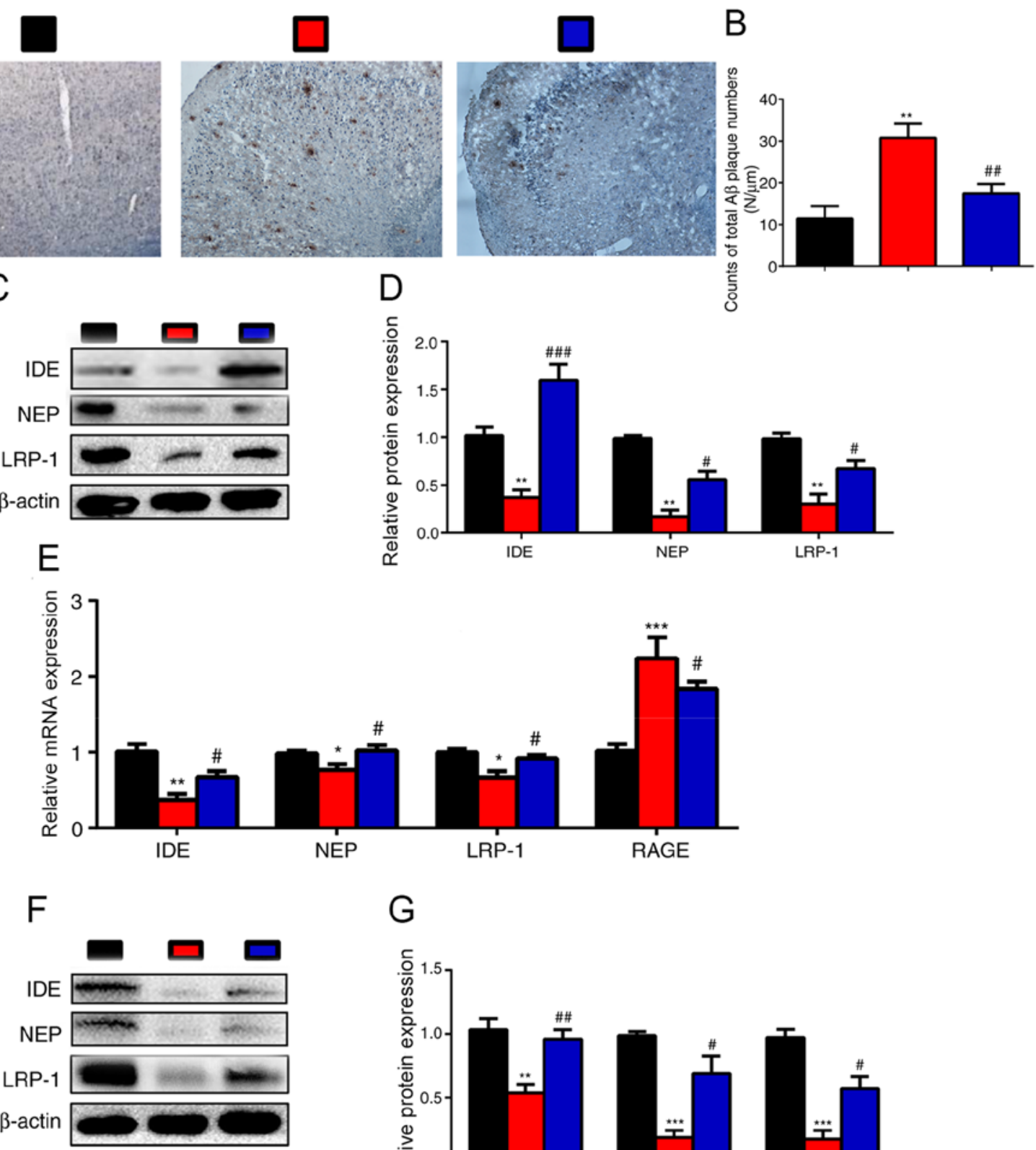

$\mathrm{H}$
G

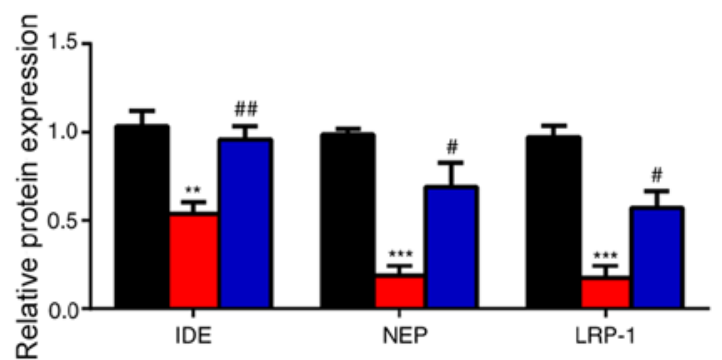

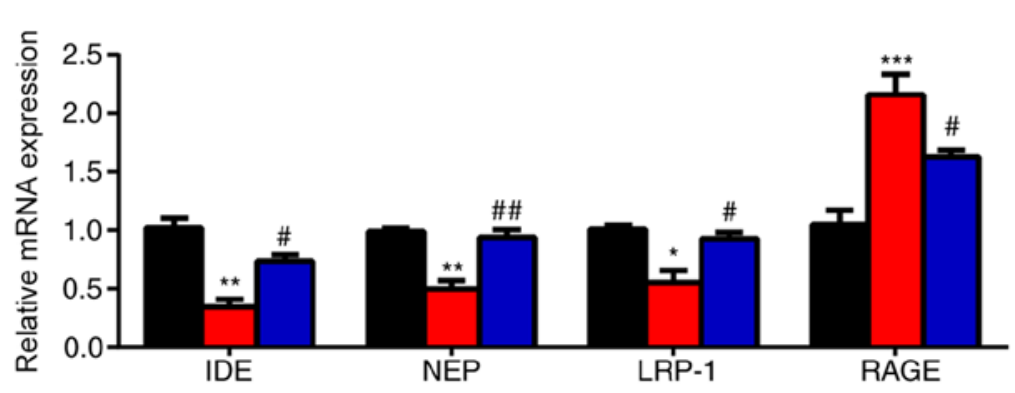

Figure 2. Exogenous CART supplements reduce A $\beta$ protein accumulation by downregulating A $\beta$ metabolism-associated enzymes in APP/PS1 mice. WT, APP/PS1 and CART-treated APP/PS1 mice (age, 8 months) were used. (A) Representative micrographs of the brain with immunohistochemical staining for $\mathrm{A} \beta$ (scale bar, $200 \mu \mathrm{m}$ ). (B) Counts of total A $\beta$ plaque numbers $(\mathrm{N} / \mu \mathrm{m})$. Relative protein expression levels of IDE, NEP and LRP-1 in the cerebral cortex were (C) determined via western blotting and (D) semi-quantified. (E) Relative mRNA expression levels of IDE, NEP, LRP-1 and RAGE in cerebral cortex extracts were measured via RT-qPCR. GAPDH was used as the internal control. Relative protein expression levels of IDE, NEP and LRP-1 in the hippocampus were (F) determined via western blotting and (G) semi-quantified. (H) Relative expression levels of IDE, NEP, LRP-1 and RAGE in hippocampus extracts were measured via RT-qPCR. GAPDH was used as the internal control. Data are presented as the mean $\pm \mathrm{SEM}$ ( $\mathrm{n}=6$ per group). ${ }^{*} \mathrm{P}<0.05,{ }^{* * *} \mathrm{P}<0.01$ and ${ }^{* * * *} \mathrm{P}<0.001$ vs. control; ${ }^{\#} \mathrm{P}<0.05,{ }^{\# \#} \mathrm{P}<0.01$ and ${ }^{\# \# \#} \mathrm{P}<0.001$ vs. APP/PS1. CART, cocaine amphetamine regulated transcript; A $\beta$, $\beta$-amyloid protein; WT, wild-type; IDE, insulin-degrading enzyme; NEP, neprilysin; LRP-1, low-density lipoprotein receptor-related protein 1; RAGE, receptor for advanced glycation end products; RT-qPCR, reverse transcription-quantitative PCR. 

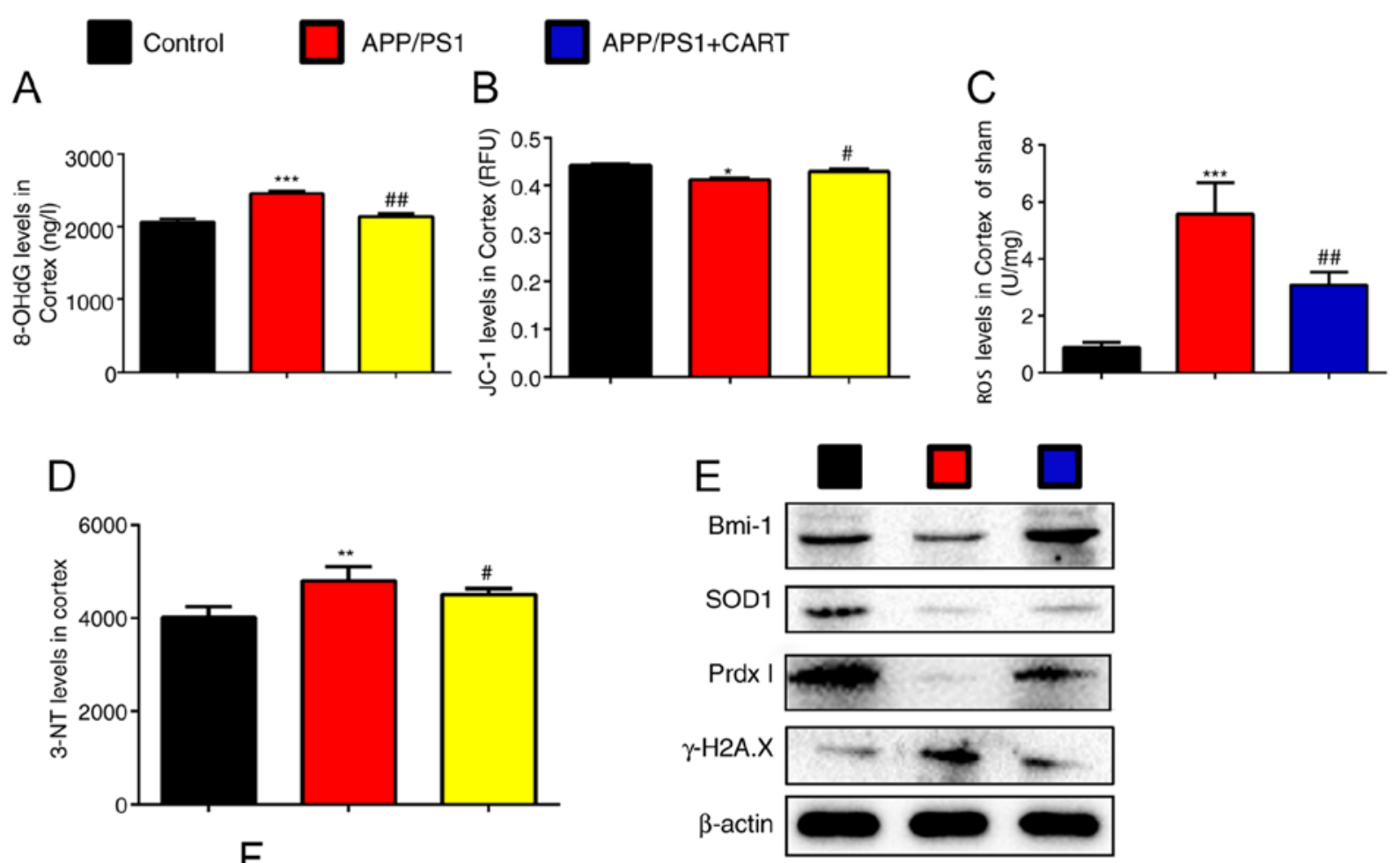

$\mathrm{F}$
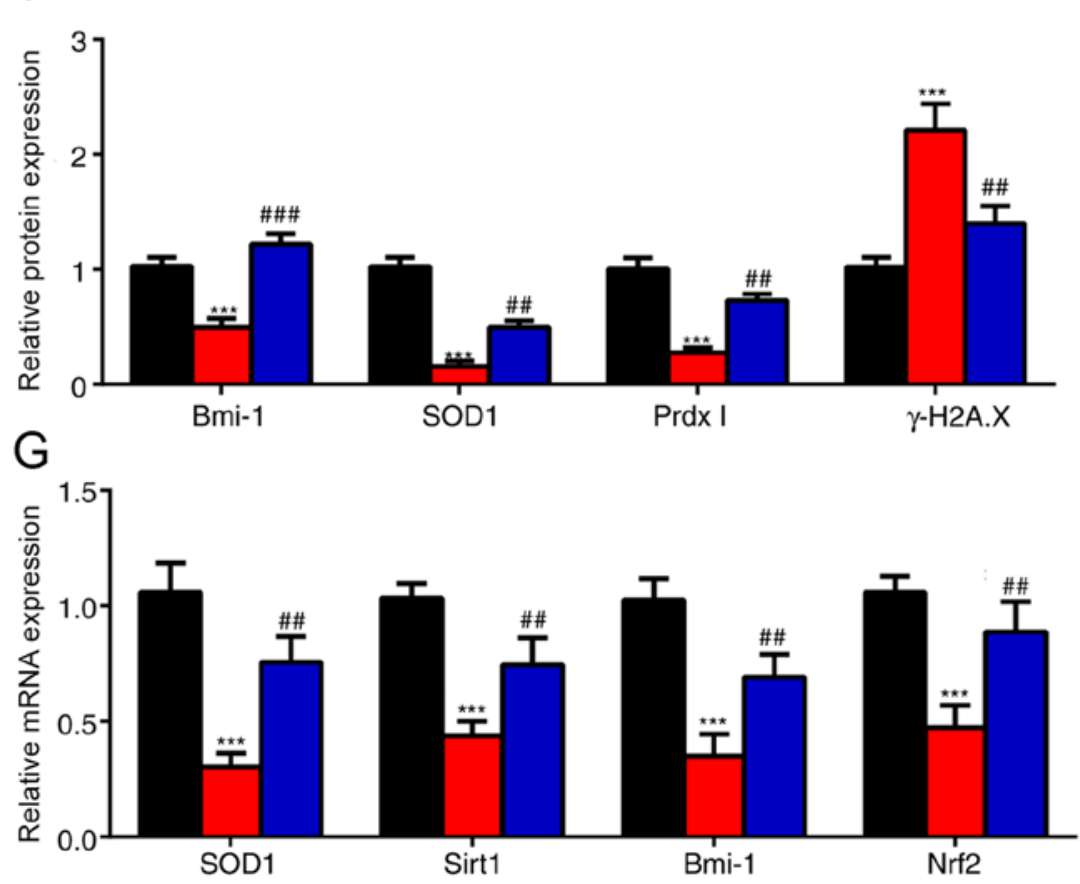

Figure 3. Exogenous CART supplements reduce oxidative stress and mitochondrial dysfunction in the cerebral cortex of APP/PS1 mice. WT, APP/PS1 and CART-treated APP/PS1 mice (age, 8 months) were used. (A) 8-OHdG level in 10\% cerebral cortex tissue homogenate. (B) The mitochondrial membrane potential (JC-1) in the cerebral cortex tissue. (C) ROS levels in cerebral cortex cells. (D) 3-NT levels in 10\% cerebral cortex tissue homogenate. Relative protein expression levels of Bmi-1, SOD1, Prdx1 and $\gamma$-H2A.X in the cerebral cortex were (E) determined via western blotting and (F) semi-quantified. (G) Relative mRNA expression levels of SOD1, Sirt1, Bmi-1 and Nrf2 in cerebral cortex extracts were measured via reverse transcription-quantitative PCR. GAPDH was used as the internal control. Data are presented as the mean \pm SEM ( $n=6$ per group). ${ }^{*} \mathrm{P}<0.05,{ }^{* *} \mathrm{P}<0.01$ and ${ }^{* * *} \mathrm{P}<0.001$ vs. control; ${ }^{*} \mathrm{P}<0.05$, ${ }^{\# \#} \mathrm{P}<0.01$ and

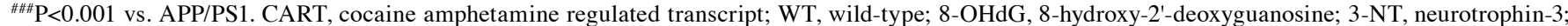
ROS, reactive oxygen species; Bmi-1, polycomb complex protein; SOD1, superoxide dismutase; Prdx1, peroxiredoxin 1; $\gamma$-H2A.X, $\gamma$-H2A histone family member X; Sirt1, sirtuin 1; Nrf2, nuclear factor erythroid 2 like 2.

were significantly decreased in APP/PS1 mice compared with WT control mice, but were significantly increased in CART-treated APP/PS1 mice compared with untreated APP/PS1 mice (Fig. 3G). $\gamma$-H2A.X protein expression levels in the cortex were significantly increased in APP/PS1 mice compared with WT control mice, but were significantly decreased in CART-treated APP/PS1 mice compared with untreated APP/PS1 mice (Fig. 3E and F). 


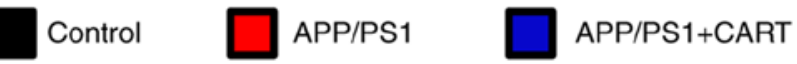

A

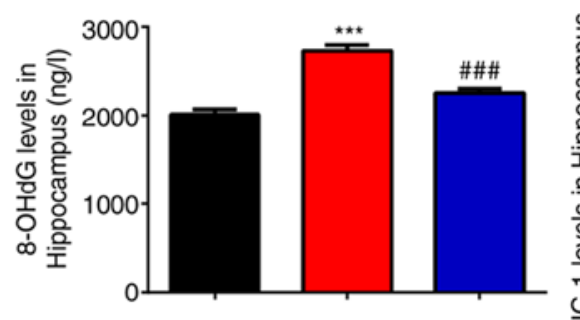

D

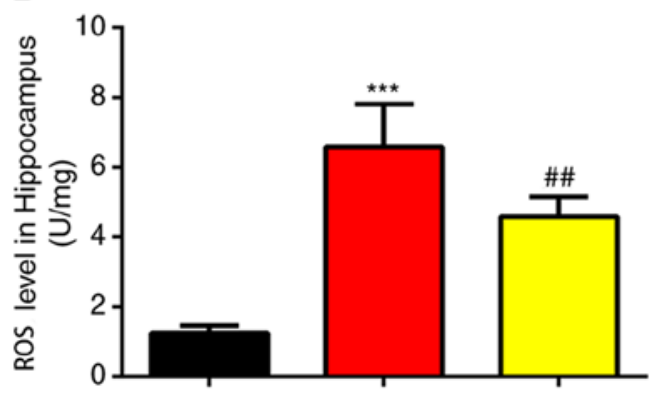

C

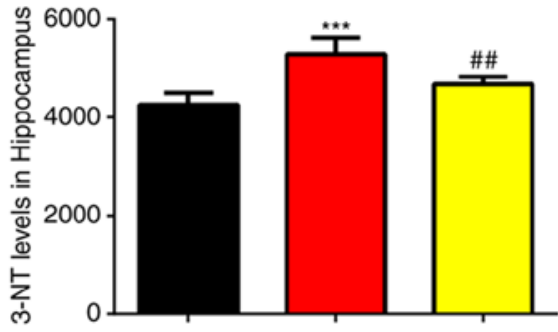

E

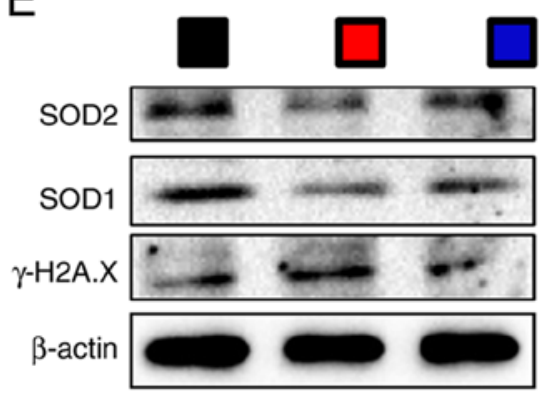

F

B

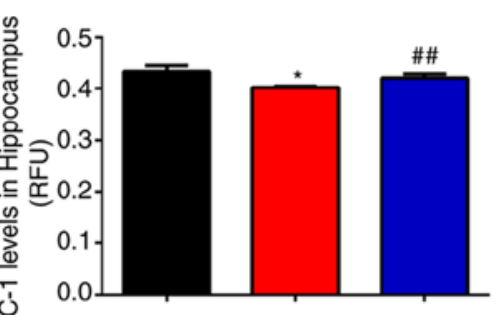



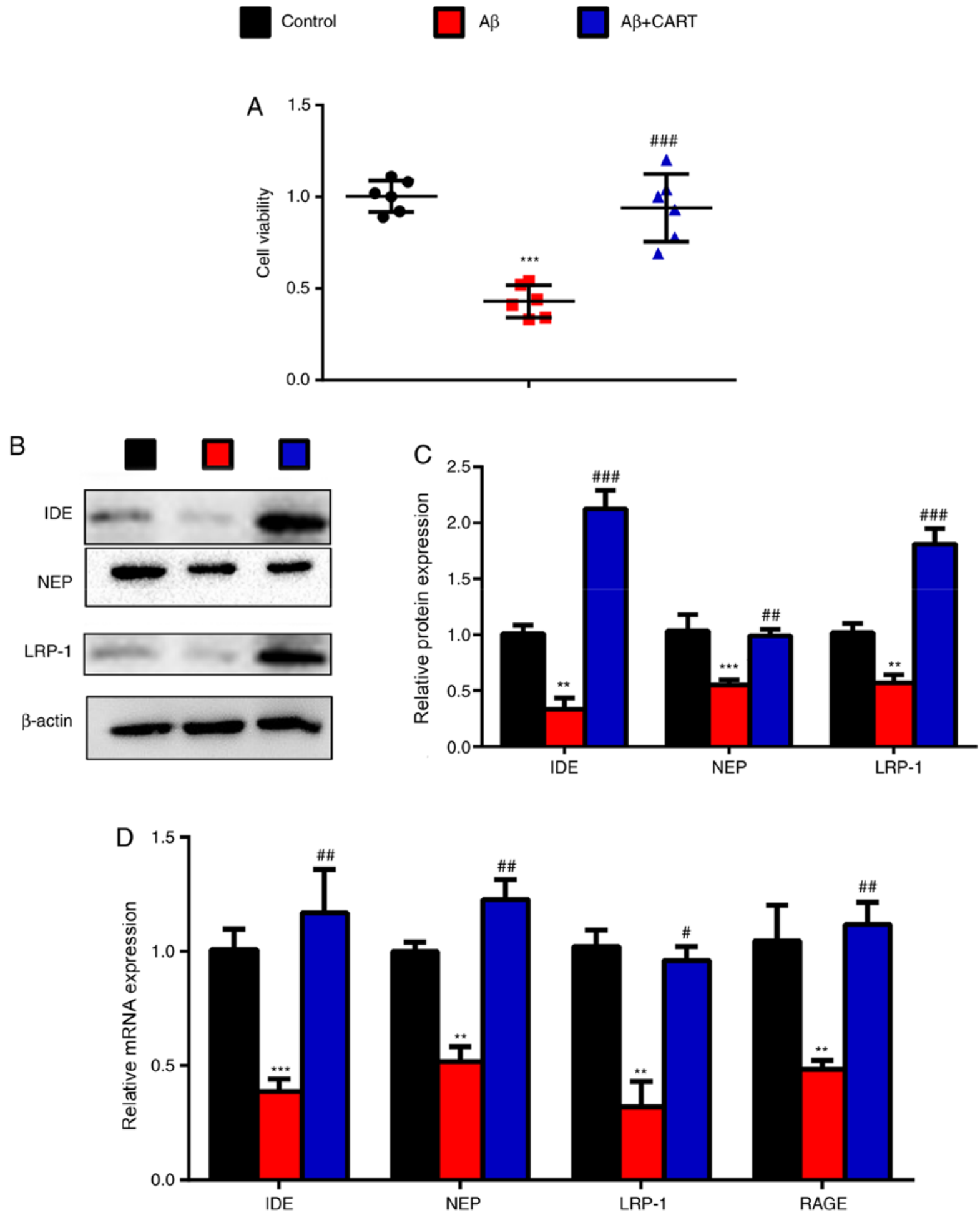

Figure 5. Treatment with CART upregulates the expression of A $\beta$ metabolism-associated enzymes in $A \beta_{1-42}$-exposed primary cortical neurons. (A) CART significantly increased cell viability in A $\beta$-exposed cultured primary cortical neurons. Relative protein expression levels of IDE, NEP and LRP-1 in cultured primary cortical neurons exposed to A $\beta$ with or without CART were (B) determined via western blotting and (C) semi-quantified. (D) Relative mRNA expression levels of IDE, NEP, LRP-1 and RAGE in cultured primary cortical neurons exposed to A $\beta$ with or without CART were measured via reverse transcription-quantitative PCR. Data are presented as the mean \pm SEM ( $n=6$ per group). ${ }^{* *} \mathrm{P}<0.01$ and ${ }^{* * * *} \mathrm{P}<0.001$ vs. control; ${ }^{\# P} \mathrm{P}<0.05$, ${ }^{\# \#} \mathrm{P}<0.01$ and ${ }^{\# \# \#} \mathrm{P}<0.001$ vs. APP/PS1. CART, cocaine amphetamine regulated transcript; A $\beta, \beta$-amyloid protein; IDE, insulin-degrading enzyme; NEP, neprilysin; LRP-1, low-density lipoprotein receptor-related protein 1; RAGE, receptor for advanced glycation end products; WT, wild-type.

but significantly decreased in CART-treated APP/PS1 mice compared with untreated APP/PS1 mice. The mitochondrial membrane potential of the hippocampus tissue was significantly decreased in APP/PS1 mice compared with WT control mice, but was significantly increased in CART-treated APP/ PS1 mice compared with untreated APP/PS1 mice (Fig. 4B).

In addition, the western blotting results indicated that protein expression levels of SOD1 and SOD2 in the hippocampus were 


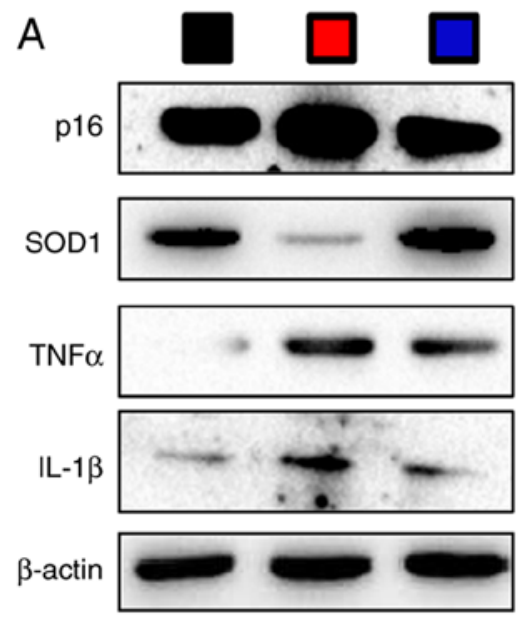

C
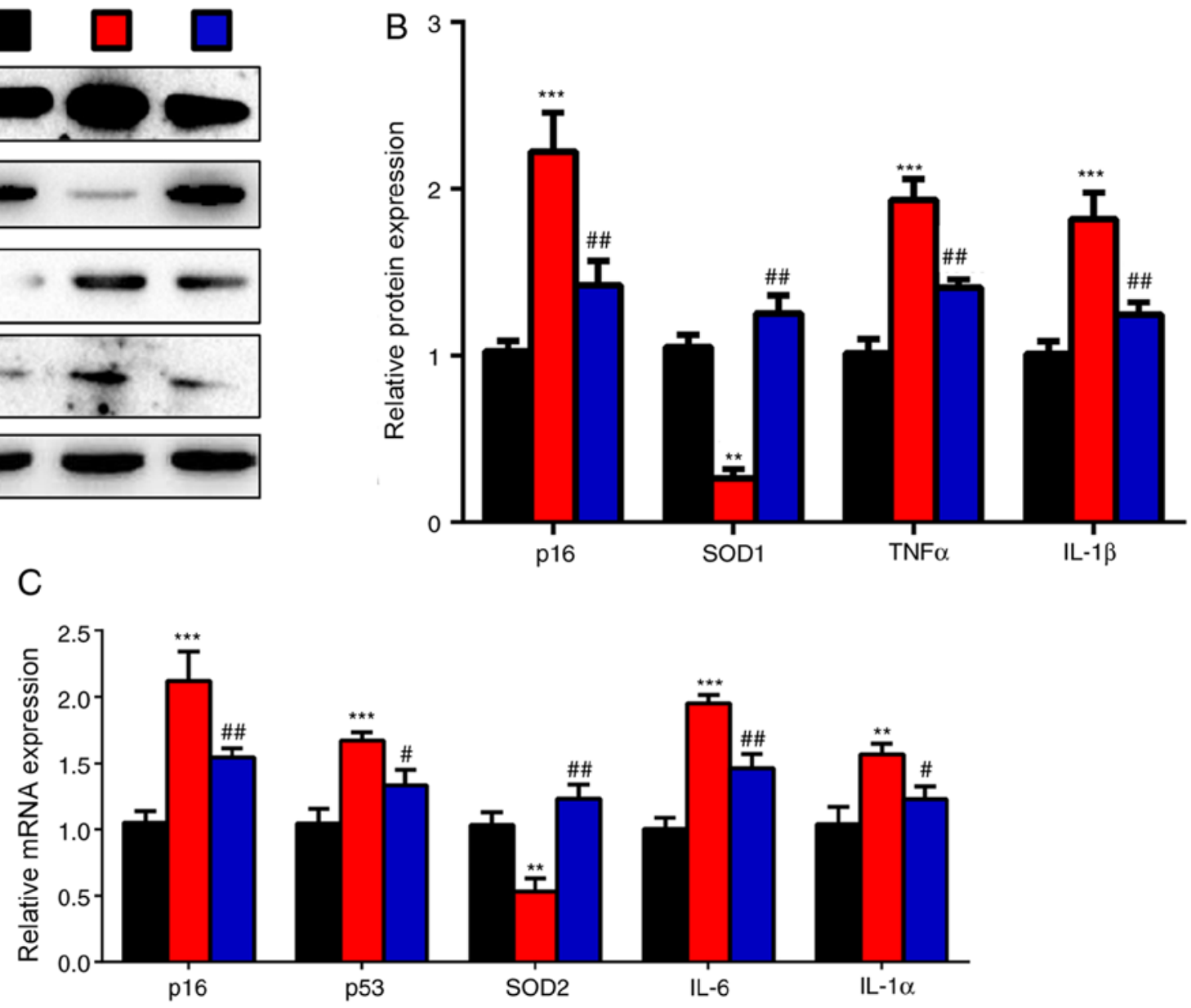

Figure 6. CART treatment reduces cell senescence and oxidative stress in $\mathrm{A} \beta_{1-42}$-exposed primary cortical neurons. Relative protein expression levels of p16, SOD1, TNF $\alpha$ and IL-1 $\beta$ in cultured primary cortical neurons exposed to A $\beta$ with or without CART were (A) determined via western blotting and (B) semi-quantified. (C) Relative mRNA expression levels of p16, p53, SOD2, IL-6 and IL-1 $\alpha$ in cultured primary cortical neurons exposed to A $\beta$ with or without CART were measured via reverse transcription-quantitative PCR. Data are presented as the mean $\pm \mathrm{SEM}$ (n=6 per group). ${ }^{* *} \mathrm{P}<0.01$ and ${ }^{* * *} \mathrm{P}<0.001$ vs. control; ${ }^{\#} \mathrm{P}<0.05$ and ${ }^{\# \#} \mathrm{P}<0.01$ vs. APP/PS1. CART, cocaine amphetamine regulated transcript; A $\beta$, $\beta$-amyloid protein; SOD, superoxide dismutase; WT, wild-type.

significantly decreased in APP/PS1 mice compared with WT control mice, but were significantly increased in CART-treated APP/PS1 mice compared with untreated APP/PS1 mice (Fig. 4E and F). Furthermore, RT-qPCR results demonstrated that SOD1, SOD2, Bmi-1 and Nrf2 mRNA expression levels in the hippocampus were significantly decreased in APP/PS1 mice compared with WT control mice, but were significantly increased in CART-treated APP/PS1 mice compared with untreated APP/PS1 mice (Fig. 4G). $\gamma$-H2A.X protein expression levels in the hippocampus were significantly increased in APP/PS1 mice compared with WT control mice, but were significantly decreased in CART-treated APP/PS1 mice compared with untreated APP/PS1 mice (Fig. 4E and F).

CART improves the expression of $A \beta$ metabolism-associated enzymes in $A \beta_{1-42}$ exposed primary cortical neurons. To validate the hypothesis, primary cortical neurons were isolated and treated with $\mathrm{A} \beta_{1-42}$ and CART. CART pretreatment significantly increased cell viability of cultured primary cortical neurons exposed to $A \beta_{1-42}$ compared with the $A \beta_{1-42}$-treated primary cortical neurons (Fig. 5A). The western blotting results showed that IDE, NEP and LRP-1 protein expression levels were significantly decreased in $A \beta_{1-42}$-treated primary cortical neurons, but were significantly increased following pretreatment with CART (Fig. 5B and C). Additionally, RT-qPCR results demonstrated that IDE, NEP, LRP-1 and RAGE mRNA expression levels were significantly decreased in $A \beta_{1-42}$-treated primary cortical neurons, but were significantly increased following pretreatment with CART (Fig. 5D).

$C A R T$ reduces cell senescence and oxidative stress in $A \beta_{1-42}$ exposed primary cortical neurons. To further investigate whether the therapeutic effects of CART on AD were mediated via oxidative stress and DNA damage, western blotting and RT-qPCR were performed. The western blotting results indicated that $\mathrm{p} 16, \mathrm{TNF} \alpha$ and IL-1 $\beta$ protein expression 


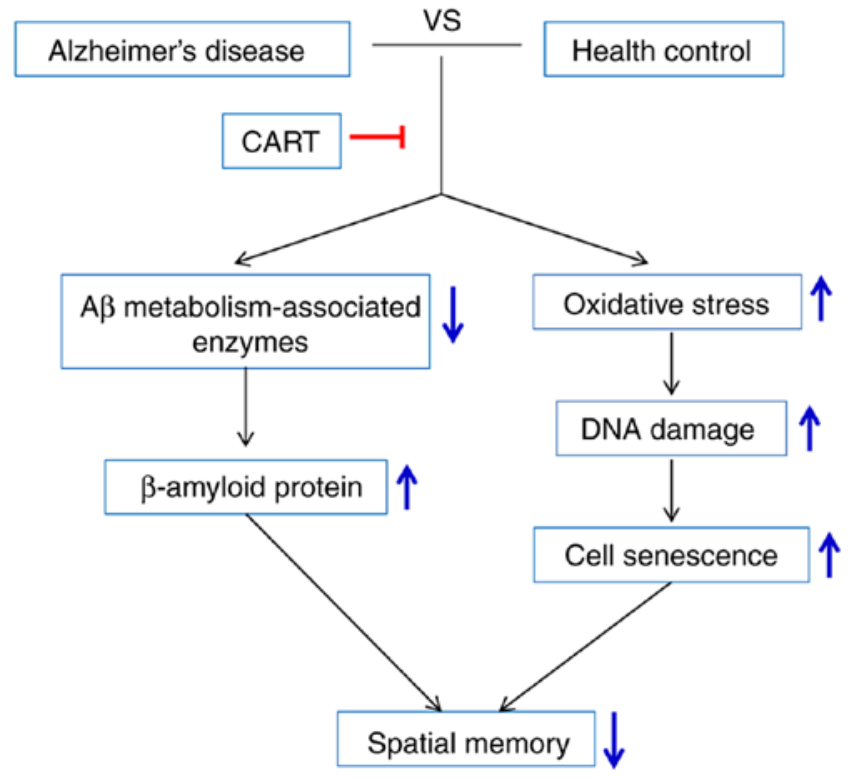

Figure 7. Model of the mechanism underlying CART-mediated improvements in memory impairment in Alzheimer's Disease. A $\beta$ metabolism-associated enzymes and oxidative stress are upregulated in Alzheimer's Disease, which results in $A \beta$ protein accumulation, and increased oxidative stress, DNA damage and cell senescence, leading to spatial memory impairment. The aforementioned processes could be rescued by CART supplements. CART, cocaine amphetamine regulated transcript; $A \beta, \beta$-amyloid protein.

levels were significantly increased in $\mathrm{A} \beta_{1-42}$-treated primary cortical neurons, but were significantly decreased following pretreatment with CART (Fig. 6A and B). Furthermore, RT-qPCR results demonstrated that p16, p53, IL-6 and IL-1 $\beta$ mRNA expression levels were significantly increased in $\mathrm{A} \beta_{1-42}$-treated primary cortical neurons, but were significantly decreased following pretreatment with CART (Fig. 6C). SOD1 protein (Fig. 6A and B) and SOD2 mRNA (Fig. 6C) expression levels were significantly decreased in the $A \beta_{1-42}$-treated primary cortical neurons, but were significantly increased following pretreatment with CART. The model of the mechanism underlying CART-mediated improvements in memory impairment in AD is presented in Fig. 7.

\section{Discussion}

In the present study, the impact of CART on spatial memory impairment in $\mathrm{AD}$ was investigated. The results indicated that the mechanism underlying the effects of exogenous CART supplements may include: i) Reducing $A \beta_{1-42}$ protein accumulation by downregulating $\mathrm{A} \beta_{1-42}$ metabolism-associated enzymes in APP/PS1 mice; ii) mediating oxidative stress, DNA damage and mitochondrial dysfunction in the cerebral cortex and hippocampus of APP/PS1 mice; and iii) reducing cell senescence and oxidative stress in $A \beta_{1-42}$-exposed primary cortical neurons. The results of the present study were consistent with previous studies that reported that $\mathrm{A} \beta$ protein accumulation, and cholinergic and neuroinflammatory oxidative stress serve a vital role in the progress of AD $(29,30)$.

$\mathrm{AD}$ is the most common cause of dementia and is characterized by onset, progressive mental decline, and personality and affective disorders (31). The pathogenesis of AD is not completely understood. $\mathrm{A} \beta$, as a toxic protein, plays a detrimental role in the pathogenesis of AD (32). Soluble A $\beta$ oligomers affect tau protein phosphorylation, affecting cytoskeletal changes (33), and thereby inducing the loss of synaptic plasticity and impairing memory function (34). Previous studies have reported that exogenous CART treatment could ameliorate memory dysfunction (4) and reduced levels of $A \beta_{1-40}$ and $A \beta_{1-42}$ could account for the neuroprotective effects of CART (24). The present study also indicated that CART improved the learning and spatial memory capacity of APP/PS mice, confirming a therapeutic effect for AD.

Age spots are the most important pathological manifestation of AD (32). The AD model used in the present study was established via an intracerebroventricular injection of $A \beta$, which simulates the pathological alterations of $A \beta$ accumulation and deposition in the brain. Several proteases have been found to be involved in the generation and turnover of $A \beta$. IDE, NEP, LRP-1 and RAGE are capable of regulating the A $\beta$ levels in both experimental models and patients with AD (35). Previous reports demonstrated that CART modulated the levels of NEP (13), IDE (14), RAGE (15) and LRP-1 (16) via inhibiting MAPK signaling pathways and activating the AKT signaling pathway (24). Similarly, the results of the present study suggested that CART regulated A $\beta$ metabolism-associated enzymes, including IDE, NEP, LRP-1 and RAGE, thereby promoting the degradation of $A \beta$, which may serve a valuable role in the treatment of AD.

A series of hypotheses have been proposed for AD, of which oxidative stress being the most predominant (35-37). When oxygen free radicals in the body are unbalanced, ROS or related substances accumulate excessively in the body, which can cause various toxic effects on the cells, resulting in reversible or irreversible damage (38). The peroxidation of lipids can inactivate ribonucleic acid, lead to DNA damage and trigger DNA mutations. In addition, the peroxidation of lipids can generate aldehydes that can combine with phosphoric acid and proteins to form lipofuscin, which when deposited in the brain leads to impaired mental ability $(39,40)$. Therefore, oxidative stress-induced damage in the brains of patients with AD serves an important role in neuronal degeneration, apoptosis, necrosis and pathogenesis. A previous study confirmed that CART activated the Nrf2/heme oxygenase 1 antioxidant signaling pathway and protected hippocampal neurons in AD (41). In accordance with a previous report (24), the present study also concluded that CART attenuated oxidative stress and maintained mitochondrial integrity, contributing to improved cognitive capacity. Moreover, CART alleviated DNA damage and cell senescence. In addition, pathological staining of $A \beta$ was performed, which increased the reliability of the present study.

In conclusion, the present study suggested that CART attenuated memory dysfunction in APP/PS1 mice by promoting $A \beta$ degradation and reducing oxidative stress and cell senescence. Therefore, CART may serve as a potential therapeutic drug for the treatment of AD.

\section{Acknowledgements}

Not applicable. 


\section{Funding}

No funding was received.

\section{Availability of data and materials}

The datasets used and/or analyzed during the current study are available from the corresponding author on reasonable request.

\section{Authors' contributions}

HJ conceptualized the study, assisted with the methodology and drafted the original manuscript. FN performed the investigation. YZ acquired the data. YX made substantial contributions to the conception and design of the study, and provided project supervision. YX and HJ confirmed the authenticity of all the raw data. All authors read and approved the final manuscript.

\section{Ethics approval and consent to participate}

All experimental procedures were approved by the Animal Ethics Committee of Drum Tower of Nanjing University (Nanjing, China).

\section{Patient consent for publication}

Not applicable.

\section{Competing interests}

The authors declare that they have no competing interests.

\section{References}

1. Barnham KJ, Masters CL and Bush AI: Neurodegenerative diseases and oxidative stress. Nat Rev Drug Discov 3: 205-214, 2004.

2. Dalakas MC, Alexopoulos $\mathrm{H}$ and Spaeth PJ: Complement in neurological disorders and emerging complement-targeted therapeutics. Nat Rev Neurol 16: 601-617, 2020.

3. Sastre M, Walter J and Gentleman SM: Interactions between APP secretases and inflammatory mediators. J Neuroinflammation 5 $25,2008$.

4. Jin JL, Liou AK, Shi Y, Yin KL, Chen L, Li LL, Zhu XL, Qian L, Yang R, Chen J and Xu Y: CART treatment improves memory and synaptic structure in APP/PS1 mice. Sci Rep 5: 10224, 2015.

5. Hijazi S, Heistek TS, Scheltens P, Neumann U, Shimshek DR, Mansvelder HD, Smit AB and van Kesteren RE: Early restoration of parvalbumin interneuron activity prevents memory loss and network hyperexcitability in a mouse model of Alzheimer's disease. Mol Psychiatry 25: 3380-3398, 2020

6. Javed I, Zhang Z, Adamcik J, Andrikopoulos N, Li Y, Otzen DE, Lin S, Mezzenga R, Davis TP, Ding F and Ke PC: Accelerated amyloid beta pathogenesis by bacterial amyloid FapC. Adv Sci (Weinh) 7: 2001299, 2020

7. Pulina MV, Hopkins M, Haroutunian V, Greengard P and Bustos V: C99 selectively accumulates in vulnerable neurons in Alzheimer's disease. Alzheimers Dement 16: 273-282, 2020.

8. Biswas SC, Shi Y, Vonsattel JP, Leung CL, Troy CM and Greene LA: Bim is elevated in Alzheimer's disease neurons and is required for beta-amyloid-induced neuronal apoptosis. J Neurosci 27: 893-900, 2007.

9. Reddy PH and Oliver DM: Amyloid beta and phosphorylated tau-induced defective autophagy and mitophagy in Alzheimer's disease. Cells 8: 488, 2019.

10. Rafii MS and Aisen PS: Recent developments in Alzheimer's disease therapeutics. BMC Med 7: 7, 2009.
11. May-Zhang LS, Kirabo A, Huang J, Linton MF, Davies SS and Murray KT: Scavenging reactive lipids to prevent oxidative injury. Annu Rev Pharmacol Toxicol: Sep 30, 2020 (Epub ahead of print). doi: 10.1146/annurev-pharmtox-031620-035348.

12. Chen X, Ji B, Hao X, Li X, Eisele F, Nyström T and Petranovic D: FMN reduces Amyloid- $\beta$ toxicity in yeast by regulating redox status and cellular metabolism. Nat Commun 11: 867, 2020.

13. Iwata N, Tsubuki S, Takaki Y, Watanabe K, Sekiguchi M, Hosoki E, Kawashima-Morishima M, Lee HJ, Hama E, Sekine-Aizawa Y and Saido TC: Identification of the major Abeta1-42-degrading catabolic pathway in brain parenchyma: Suppression leads to biochemical and pathological deposition. Nat Med 6: 143-150, 2000.

14. Deprez-Poulain R, Hennuyer N, Bosc D, Liang WG, Enée E, Marechal X, Charton J, Totobenazara J, Berte G, Jahklal J, et al: Catalytic site inhibition of insulin-degrading enzyme by a small molecule induces glucose intolerance in mice. Nat Commun 6: 8250,2015

15. Ali T, Badshah H, Kim TH and Kim MO: Melatonin attenuates D-galactose-induced memory impairment, neuroinflammation and neurodegeneration via RAGE/NF-K B/JNK signaling pathway in aging mouse model. J Pineal Res 58: 71-85, 2015.

16. Yan FL, Zheng Y and Zhao FD: Effects of Ginkgo biloba extract EGb761 on expression of RAGE and LRP-1 in cerebral microvascular endothelial cells under chronic hypoxia and hypoglycemia. Acta Neuropathol 116: 529-535, 2008

17. Dallvechia-Adams S, Kuhar MJ and Smith Y: Cocaine- and amphetamine-regulated transcript peptide projections in the ventral midbrain: Colocalization with gamma-aminobutyric acid, melanin-concentrating hormone, dynorphin, and synaptic interactions with dopamine neurons. J Comp Neurol 448: 360-372, 2002.

18. Zhang Z, Cao X, Bao X, Zhang Y, Xu Y and Sha D: Cocaine- and amphetamine-regulated transcript protects synaptic structures in neurons after ischemic cerebral injury. Neuropeptides 81: $102023,2020$.

19. Hunter RG and Kuhar MJ: CART peptides as targets for CNS drug development. Current drug targets. Curr Drug Targets CNS Neurol Disord 2: 201-205, 2003.

20. Janiuk I and Mlynek K: Immunodetection of cocaine- and amphetamine-regulated transcript in bovine pancreas. Acta Histochem 117: 545-550, 2015.

21. Gilon P: Cocaine- and amphetamine-regulated transcript: A novel regulator of energy homeostasis expressed in a subpopulation of pancreatic islet cells. Diabetologia 59: 1855-1859, 2016.

22. Rząp D, Czajkowska M and Całka J: Neurochemical plasticity of nNOS-, VIP- and CART-immunoreactive neurons following prolonged acetylsalicylic acid supplementation in the porcine jejunum. Int J Mol Sci 21: 2157, 2020.

23. Hsieh YS, Chen PN, Yu CH, Chen $\mathrm{CH}$, Tsai TT and Kuo DY: Involvement of oxidative stress in the regulation of NPY/CART-mediated appetite control in amphetamine-treated rats. Neurotoxicology 48: 131-141, 2015.

24. Yin KL, Jin JL, Zhu XL, Yu L, Wang S, Qian L, Han L and Xu Y: CART modulates beta-amyloid metabolism-associated enzymes and attenuates memory deficits in APP/PS1 mice. Neurol Res 39: 885-894, 2017.

25. Sha DJ, Li LL, Ye L, Li R and Xu Y: Icariin inhibits neurotoxicity of beta-amyloid by upregulating cocaine-regulated and amphetamine-regulated transcripts. Neuroreport 20: 1564-1567, 2009.

26. Wang GH, Jiang XY, Pu HJ, Zhang W, An C, Hu X, Liou AK, Leak RK, Gao Y and Chen J: Scriptaid, a novel histone deacetylase inhibitor, protects against traumatic brain injury via modulation of PTEN and AKT pathway: Scriptaid protects against TBI via AKT. Neurotherapeutics 10: 124-142, 2013.

27. Xu Y, Zhang W, Klaus J, Young J, Koerner I, Sheldahl LC, Hurn PD, Martínez-Murillo F and Alkayed NJ: Role of cocaineand amphetamine-regulated transcript in estradiol-mediated neuroprotection. Proc Natl Acad Sci USA 103: 14489-14494, 2006

28. Sun W, Sun W, Liu J, Zhou X, Xiao Y, Karaplis A, Pollak MR, Brown E, Goltzman D and Miao D: Alterations in phosphorus, calcium and PTHrP contribute to defects in dental and dental alveolar bone formation in calcium-sensing receptor-deficient mice. Development 137: 985-992, 2010.

29. Müller S, Preische O, Sohrabi HR, Gräber S, Jucker M, Ringman JM, Martins RN, McDade E, Schofield PR, Ghetti B, et al: Relationship between physical activity, cognition, and Alzheimer pathology in autosomal dominant Alzheimer's disease. Alzheimers Dement 14: 1427-1437, 2018. 
30. Vöglein J, Paumier K, Jucker M, Preische O, McDade E, Hassenstab J, Benzinger TL, Noble JM, Berman SB, Graff-Radford NR, et al: Clinical, pathophysiological and genetic features of motor symptoms in autosomal dominant Alzheimer's disease. Brain 142: 1429-1440, 2019.

31. Lane CA, Hardy J and Schott JM: Alzheimer's disease. Eur J Neurol 25: 59-70, 2018.

32. Haass C and Selkoe DJ: Soluble protein oligomers in neurodegeneration: Lessons from the Alzheimer's amyloid beta-peptide. Nat Rev Mol Cell Biol 8: 101-112, 2007.

33. Jin M, Shepardson N, Yang T, Chen G, Walsh D and Selkoe DJ: Soluble amyloid beta-protein dimers isolated from Alzheimer cortex directly induce Tau hyperphosphorylation and neuritic degeneration. Proc Natl Acad Sci USA 108: 5819-5824, 2011.

34. Zempel H, Thies E, Mandelkow E and Mandelkow EM: Abeta oligomers cause localized $\mathrm{Ca}(2+)$ elevation, missorting of endogenous Tau into dendrites, Tau phosphorylation, and destruction of microtubules and spines. J Neurosci 30: 11938-11950, 2010.

35. Barage SH and Sonawane KD: Amyloid cascade hypothesis: Pathogenesis and therapeutic strategies in Alzheimer's disease. Neuropeptides 52: 1-18, 2015.

36. Tönnies E and Trushina E: Oxidative stress, synaptic dysfunction, and Alzheimer's disease. J Alzheimers Dis 57: 1105-1121, 2017.
37. Yin F, Sancheti H, Patil I and Cadenas E: Energy metabolism and inflammation in brain aging and Alzheimer's disease. Free Radic Biol Med 100: 108-122, 2016.

38. Chen L, Yang R, Qiao W, Zhang W, Chen J, Mao L, Goltzman D and Miao D: 1,25-Dihydroxyvitamin D exerts an antiaging role by activation of Nrf2-antioxidant signaling and inactivation of p16/p53-senescence signaling. Aging Cell 18: e12951, 2019.

39. Raefsky SM, Furman R, Milne G, Pollock E, Axelsen P, Mattson MP and Shchepinov MS: Deuterated polyunsaturated fatty acids reduce brain lipid peroxidation and hippocampal amyloid $\beta$-peptide levels, without discernable behavioral effects in an APP/PS1 mutant transgenic mouse model of Alzheimer's disease. Neurobiol Aging 66: 165-176, 2018.

40. Hardas SS, Sultana R, Clark AM, Beckett TL, Szweda LI, Murphy MP and Butterfield DA: Oxidative modification of lipoic acid by HNE in Alzheimer disease brain. Redox Biol 1: 80-85, 2013.

41. Jiao W, Wang Y, Kong L, Ou-Yang T, Meng Q, Fu Q and Hu Z: CART peptide activates the $\mathrm{Nrf} 2 / \mathrm{HO}-1$ antioxidant pathway and protects hippocampal neurons in a rat model of Alzheimer's disease. Biochem Biophys Res Commun 501: 1016-1022, 2018.

(7) (9) This work is licensed under a Creative Common Attribution 4.0 International (CC BY-NC 4.0) License 